\title{
Political Cycles, Investor Sentiment, and Stock Market Returns
}

\author{
Frederick Adjei ${ }^{1, *}$, Mavis Adjei $^{2}$ \\ ${ }^{1}$ Economics and Finance Department, Southeast Missouri State University, Cape Girardeau, USA \\ ${ }^{2}$ Marketing Department, Southern Illinois University Carbondale, Carbondale, USA \\ *Corresponding author: fadjei@semo.edu
}

\begin{abstract}
In this study, we examine the relationships among political cycles, investor sentiment, and stock market returns. We uncover that the variable: change in investor sentiment levels, is a mediator for the relationship between political cycles and stock market returns. We establish that political cycles impact stock market returns through two channels. First, there is a direct impact of fiscal and regulatory policies on corporate fundamentals which is reflected in stock prices, and second, there is an indirect impact through the change in investor sentiment levels which in turn impacts stock prices. Additionally, we empirically examine the relationship between presidential elections cycles and investor sentiment, and find that investor sentiment levels are lower and improve during Democratic presidential terms and are higher and decline during Republican presidential terms.
\end{abstract}

Keywords: political cycles, investor sentiment, stock market returns

Cite This Article: Frederick Adjei, and Mavis Adjei, "Political Cycles, Investor Sentiment, and Stock Market Returns.” Journal of Finance and Economics, vol. 5, no. 1 (2017): 1-10. doi: 10.12691/jfe-5-1-1.

\section{Introduction}

Towards presidential elections, the media is filled with analyses on whether a Democrat or a Republican president is better for the stock market. Extant research such as [1] and [2] attempt to answer this question by examining the correlation between stock returns and political cycles. Additionally, [3], [4], and [5] establish that primarily, the differences in fiscal and regulatory policies of the presidential political parties are reflected in the macroeconomy and hence stock market returns.

However, a vastly ignored but important factor in this discussion is the role of investor sentiment in moderating the relation between presidential political cycles and stock market returns. Naturally, the presidential political party invokes a degree of sentiment in an investor, with the valence depending on whether the investor's political affiliation is the same as the sitting president's political party or not, and for a politically unaffiliated investor, their sentiment may depend on their perceptions of the macroeconomic growth potentials of the fiscal and regulatory policies of the sitting president's political party. [6] suggests that investor sentiment has a significant role in determining asset prices. Thus a secondary channel through which the presidential political party affects stock market returns may be through the effect on investor sentiment.

Unfortunately, the relation between political cycles and investor sentiment has not been answered by the extant academic research. This study answers this question by empirically examining the relations among presidential political cycles, investor sentiment, and stock market returns.
Until recently, investor sentiment; defined as a belief about investment risk and future cash flows that cannot be explained by current data (see [6]), had no role in asset pricing models. Classical asset pricing models assumed investors are rational, will diversify to reduce the risk of their portfolios, and the cross-section of systematic risk will determine the cross-section of expected returns in assets. And if any irrational investors exist, the effects of their actions will be nullified by that of arbitrageurs in the market. Hence, investor sentiment had no role in determining prices. However, recent evidence in [6] suggests that investor sentiment has a significant role in determining asset prices.

After controlling for macroeconomic factors, we find that the presidential political cycle is correlated with investor sentiment levels as well as investor sentiment changes. Investor sentiment levels are lower during Democratic presidential terms than during Republican presidential terms. Specifically, investor sentiment is low at the commencement of a Democratic presidential term and improves during the course of the term. By the end of a Democratic presidential term, investor sentiment is high and declines during the subsequent Republican presidential term.

We also find that investor sentiment is generally higher following a change in the political party in the White House. Finally, consistent with previous studies, we find that realized as well as excess returns are higher during Democratic presidencies than during Republican presidencies. The mean of the investor sentiment level index is negative and market returns are positive and high during Democratic presidencies and may explain the counterintuitive negative correlation between beginning of period investor sentiment level index and stock market returns reported by [7]. 
This study contributes to the extant literature on the predictive power of presidential political cycles, by documenting a relation between political cycles and investor sentiment. Second, we provide more evidence on the relation between political cycles and stock market returns. Third, we find that investor sentiment is a mediator for the relationship between political cycles and stock market returns. We review the extant literature in the next section.

\section{Literature Review}

This is the first study, to the best of our knowledge, to examine the relation between political cycles and investor sentiment. There are a few studies on the relation between political cycles and stock market returns.

Theoretically, political cycles may cause stock return differences through differences in regulatory and fiscal policies. According to [3] Democrats and Republicans may differ in policies relating to the safety net, taxes, and government spending. Additionally, [4] and [5] offer theoretical literature on the relation between political cycles and the macroeconomy, and suggest that the ideological orientation of governments and the competition between political parties, particularly in two-party systems, has an impact on unemployment, inflation, economic growth, fiscal and monetary policy.

Empirically, [7] and [8] document the stock return differences, by showing that REITs returns are higher and market volatility is higher during a Republican president's term. The aforementioned studies do not control for macroeconomic variables in their analyses. However, [7] formally examine the relation between political cycles and stock market returns, controlling for macroeconomic factors, and still find, consistent with the earlier studies, that stock returns are higher during Democratic presidencies.

Following [9], [10] also examine the relation between political cycles and stock returns and find that there are predictable variations in stock returns and cash flows over the political cycles. Belo et al. find that during Democratic presidencies, companies with high government exposure have higher stock returns and cash flows, while during Republican presidencies companies with high government exposure have lower stock returns and cash flows.

Research in behavioral finance identifies that investors are subject to sentiment [see [11]] and investor sentiment is a significant factor in asset pricing [see [1]]. Several studies attempt to establish an investor sentiment measure and so the behavioral finance literature has various proxies for investor sentiment. [12] present closed-end fund discounts as a measure of investor sentiment. Lee et al. argue that some of the features of the discounts are motivated by investor sentiment. [13] argue that in a market with short-sale constraints, investors will only add liquidity if they are optimistic about the market, and suggest that liquidity is a measure of investor sentiment. [14] cites high first day returns on IPOs as an indicator of investor enthusiasm about the market.

A comprehensive measure of investor sentiment is presented by [6], who create a composite index of investor sentiment based on multiple indicators. We use this index in our study.

\section{Hypothesis Development}

Our primary hypothesis is theoretically motivated by [3]. [3] argues that Republicans and Democrats may differ in policies relating to the safety net, taxes, and government spending. Arguably, most republicans believe lower income tax rates, a smaller safety net, and a low minimum wage are better for economic growth and hence better for the stock market. Republicans believe stimulating the economy should be by means of private spending rather than government spending and favor a laissez-faire economic model. This belief in private business seems to be at the core of the Republican Party ideology and is echoed in the 1856 slogan "free labor, free land, free men".

Debatably, democrats on the other hand believe progressive tax rates; taxing the wealthier more, a larger safety net to reduce income inequality, and higher minimum wage are better for economic growth. The unambiguous differences between Democrat and Republican economic policies and the fact that each party believes their policies are better for the stock market makes this study interesting. Additionally, investor confidence that a political party's policies will grow the economy may be reflected in investors' economic outlook as captured by investor sentiment during a president's tenure in office. Following the above discussion, we hypothesize that

H1: Investor sentiment is correlated with the presidential political cycle.

When a president begins his/her tenure in office, investors observe the president's leadership on fiscal and regulatory policies and begin to form opinions regarding economic growth prospects. By the third year, investors are well-informed of the effects of the president's economic policies, and depending on whether these effects are expansionary or contractionary investor sentiment will increase or decrease, respectively.

H2: For a given president, investor sentiment during the first year in office will be different from the investor sentiment during the third year in office.

Additionally, consistent with [9] and [10] findings that the differences in presidential policies translate into differences in stock market returns, we hypothesize that H3: The average stock market return during a Democratic presidency is statistically different from the average stock market return during a Republican presidency.

Next, we extend our study to present a behavioral finance link between political cycles and stock returns by suggesting that the effect of political cycles on stock returns is twofold; first, by the direct effects of fiscal policies on corporate fundamentals (see [10]) and second, by an indirect effect through investor sentiment. The indirect-link hypothesis suggests that investor sentiment may partially mediate the link between political cycles and stock returns. We control for stock return in the previous month to control for the effect of market momentum on investor sentiment, and examine the links among political cycles, investor sentiment, and stock returns.

H4: Investor sentiment is a mediator between political cycles and stock market returns.

Next, we describe the variables and methods used in the study. 
Table 1. Summary Statistics

Panel A: Political Cycle Data

\begin{tabular}{|c|c|c|c|}
\hline President & \multicolumn{2}{|c|}{ Tenure in Months } & \\
\hline Democrat & \multicolumn{2}{|l|}{228} & \\
\hline Republican & \multicolumn{2}{|l|}{336} & \\
\hline$N$ & \multicolumn{2}{|l|}{564} & \\
\hline \multicolumn{4}{|c|}{ Panel B: Sentiment and Returns Variables } \\
\hline Variable & Mean & Median & Std. Dev. \\
\hline Sent & 0.003 & -0.013 & 0.998 \\
\hline sent' & 0.003 & 0.015 & 0.999 \\
\hline$V W R-R F$ & 0.428 & 0.750 & 0.594 \\
\hline$V W R$ & 0.861 & 1.170 & 0.583 \\
\hline$R F$ & 0.432 & 0.420 & 0.249 \\
\hline \multicolumn{4}{|c|}{ Panel C: Control Variables in Percentage Points } \\
\hline Log div/price & -3.161 & -3.091 & 0.396 \\
\hline Term Spread & 1.369 & 1.340 & 0.320 \\
\hline Relative Rate & 0.010 & -0.027 & 0.601 \\
\hline Inflation Rate & 3.056 & 2.790 & 0.561 \\
\hline Default Spread & 1.200 & 0.943 & 0.678 \\
\hline
\end{tabular}

Table 1 reports the summary statistics of the variables used in the study. Panel A reports the total presidential tenure in months per political party during the sample period. Panels B and C report mean, median and standard deviation (Std. Dev.) for sentiment index, returns, and control variables. Returns are expressed in percentage points. For robustness, we use two indices of the sentiment level index. The first index (sent) is based on proxies of investor sentiment but not orthogonalized to macroeconomic trends. The second index (sent') is also based on proxies of investor sentiment and orthogonalized to macroeconomic trends. The data is monthly from January 1965 to December 2011. For stock market returns, we use the monthly returns of value-weighted (VWR) portfolios from CRSP. For the risk-free rate $(R F)$, we use the three-month Treasury bill rate. The term spread is the difference between the yield to maturity of a 10-year Treasury note and a three-month Treasury bill, the default spread is the difference between yields of BAA-rated bonds and AAArated bonds, the relative interest rate calculated as the deviation of the three-month Treasury bill rate from its one-year moving average, the inflation rate is obtained from FRED and the log dividend-price ratio is the log of the dividend-price ratio obtained from CRSP.

\section{Data}

In this section, we describe the data and main variables we use in the study. Following [9] we group the data into political variables, financial variables, and control variables. Summary statistics are presented in Table 1. All variables are at monthly frequency.

\subsection{Political Variables}

The sample period consists of 13 elections; 5 Democratic and 8 Republican presidents. Data on historical election results are obtained from the U.S. Electoral College archives. The data spans 1965:01 to 2011:12, 564 monthly observations.

\subsection{Financial Variables}

To measure investor sentiment, we use the [6] beginning of period sentiment index data available on
Jeffrey Wurgler's website. For robustness, we use two investor sentiment level and two investor sentiment changes indexes. The first sentiment level index (sent) is based on proxies of investor sentiment but not orthogonalized to macroeconomic trends. The second sentiment level index (sent') is also based on proxies of investor sentiment and orthogonalized to macroeconomic trends. The first sentiment changes index (sentc) is based on changes in non-orthogonalized investor sentiment level index. The second sentiment changes index (sentc') is based on based on changes in orthogonalized investor sentiment level index. The sentiment data availability limits our analysis to the following date range: 1965:01 to 2011:12.

We also analyze realized and excess stock market returns. We use the monthly returns of the value-weighted $(V W R)$ portfolios from CRSP. For the risk-free rate $(\boldsymbol{R F})$, we obtain the three-month Treasury bill rate from the Federal Reserve Economic Data [FRED].

\subsection{Control Variables}

For macroeconomic conditioning variables, we follow [9]. We use the term spread which is the difference between the yield to maturity of a 10-year Treasury note and a three-month Treasury bill, the default spread which is the difference between yields of BAA-rated bonds and AAA-rated bonds, the relative interest rate calculated as the deviation of the three-month Treasury bill rate from its one-year moving average, the inflation rate, and the log dividend-price ratio. The dividend-price ratio data are from CRSP and the data for the other macroeconomic conditioning variables are from FRED.

\section{Main Findings}

In this study, we present a behavioral finance link between political cycles and stock returns, by showing that political cycles affect investor sentiment and suggest that the effect of political cycles on stock returns may also be through their effect on investor sentiment. In this section, we present the main findings.

\subsection{Political Cycles and Investor Sentiment Level}

We begin by examining the relation between political cycles and investor sentiment. [9] find that the cycle of the controlling political party in Congress has no significant impact on stock returns. Hence, following [1], [7], and [8], we use the presidential political cycles as the political variable. First, controlling for macroeconomic factors, we regress investor sentiment level index on a presidential party dummy. We employ contemporaneous independent variables because of the almost instantaneous effects of politics as well as macroeconomic factors on investor sentiment. We use the following primary regression model correcting for heteroskedasticity in the error term:

$$
\text { sent }_{t}=\beta_{0}+\beta_{1} \operatorname{DemP}_{t}+\beta_{2-6} C V_{t}+\varepsilon_{t}
$$

where sent $t_{t}$ is the investor sentiment level index in month $t$. DemP $_{t}$ is set to 1 in month $t$ if the president is a Democrat; 
$\operatorname{DemP}_{t}$ is set to 0 otherwise, and $C V_{t}$ is the set of business cycle control variables defined earlier. $\varepsilon_{t}$ is the heteroskedastic error term in month $t$.

Under the null hypothesis that political cycles have no effect on investor sentiment level, we should have a regression result of $\beta_{1}=0$. The results of regression (1) are presented in column 1 of Table 2 . The negative and statistically significant $\beta_{1}$ coefficient suggests that investor sentiment levels are lower during Democratic presidential terms than during Republican terms.

As investors learn more about a president's policies and observe the effects, their sentiment may change, improving if the policies are deemed expansionary, and dampening if the policies are deemed contractionary. To explore these effects, we examine investor sentiment at different times during a president's tenure. We examine investor sentiment during the first year and third year. Comparing the first and fourth year of a presidency would allow us to observe the most investor learning, but because the fourth year is an election year, the effects of the election campaign may confound the effects of a president's policies on investor sentiment. To investigate the investor learning effects, we incorporate first year and third year dummy variables in our primary regression.

Additionally, following the [3] assertion that Democrats and Republicans may differ in their policies relating to the safety net, taxes, and government spending, we hypothesize that a change in the political party in the White House, will suggest a change in economic policy, and hence, trigger a change in investor sentiment. We investigate this change by incorporating a dummy variable for a change in the political party in the White House in our primary regression, leading to the following model;

$$
\begin{aligned}
\text { sent }_{t}= & \beta_{0}+\beta_{1} \text { DemP }_{t}+\beta_{2} \text { FirstYear }_{t}+\beta_{3} \text { ThirdYear }_{t} \\
& +\beta_{4} \text { Change }_{t}+\beta_{5-9} C V_{t}+\varepsilon_{t}
\end{aligned}
$$

where sent $t_{t}$ is the investor sentiment level index in month $t$, $\operatorname{DemP}_{t}$ is set to 1 in month $t$ if the president is a Democrat; $\operatorname{DemP}_{t}$ is set to 0 otherwise, FirstYear ${ }_{t}$ is a dummy variable which is set to 1 if month $t$ is in the first year of president's tenure, and 0; otherwise, ThirdYear ${ }_{t}$ is a dummy variable which is set to 1 if month $t$ is the third year of president's tenure, and 0; otherwise, Change $e_{t}$ is set to 1 at month $t$ if the president is of a different political party than his predecessor; and 0 ; otherwise, and $C V_{t}$ is the set of business cycle controls defined earlier. $\varepsilon_{t}$ is the heteroskedastic error term in month $t$.

The results of regression (2) are presented in column 2 of Table 2. The coefficient estimates for the first year dummy are not statistically different from zero, suggesting that investor sentiment in the first year of a president's tenure is not different compared to the mean investor sentiment for the rest of the term. This finding is not surprising; investors typically begin to learn about a president in the first year and form opinions of markets prospects.

However, the coefficient estimates for the third year dummy are negative and statistically significant at the $1 \%$ level, indicating that investor sentiment generally declines in the third year. By the third year, investors are well-informed of the effects of the president's policy on the economy, and regardless of the political party, investor optimism is generally lower suggesting that presidents generally do not live up to investor expectations. Additionally, the coefficients of the change dummy are positive and statistically significant at the $1 \%$ level, indicating that investors are more optimistic if there is a change in the political party in the White House.

Table 2. Relationship between Political Cycles and Investor

\begin{tabular}{|c|c|c|c|c|}
\hline & \multicolumn{2}{|c|}{ (1) } & \multicolumn{2}{|c|}{ (2) } \\
\hline & sent & sent' & Sent & sent' \\
\hline $\operatorname{DemP}_{t}$ & $\begin{array}{c}-0.343 \\
{[0.000]}\end{array}$ & $\begin{array}{c}-0.362 \\
{[0.000]}\end{array}$ & $\begin{array}{c}-0.420 \\
{[0.000]}\end{array}$ & $\begin{array}{l}-0.449 \\
{[0.000]}\end{array}$ \\
\hline First Year & & & $\begin{array}{c}-0.091 \\
{[0.443]}\end{array}$ & $\begin{array}{c}-0.199 \\
{[0.106]}\end{array}$ \\
\hline Third Year & & & $\begin{array}{c}-0.241 \\
{[0.005]}\end{array}$ & $\begin{array}{c}-0.332 \\
{[0.000]}\end{array}$ \\
\hline Change & & & $\begin{array}{c}0.662 \\
{[0.000]}\end{array}$ & $\begin{array}{c}0.719 \\
{[0.000]}\end{array}$ \\
\hline Log div/price & $\begin{array}{c}-0.369 \\
{[0.002]}\end{array}$ & $\begin{array}{c}-0.258 \\
{[0.034]}\end{array}$ & $\begin{array}{c}-0.277 \\
{[0.016]}\end{array}$ & $\begin{array}{c}-0.148 \\
{[0.194]}\end{array}$ \\
\hline Term Spread & $\begin{array}{c}-0.160 \\
{[0.000]}\end{array}$ & $\begin{array}{c}-0.141 \\
{[0.000]}\end{array}$ & $\begin{array}{c}-0.175 \\
{[0.000]}\end{array}$ & $\begin{array}{c}-0.161 \\
{[0.000]}\end{array}$ \\
\hline Relative Rate & $\begin{array}{c}0.027 \\
{[0.647]}\end{array}$ & $\begin{array}{c}0.044 \\
{[0.482]}\end{array}$ & $\begin{array}{c}0.018 \\
{[0.762]}\end{array}$ & $\begin{array}{c}0.031 \\
{[0.604]}\end{array}$ \\
\hline Inflation Rate & $\begin{array}{c}-0.057 \\
{[0.013]}\end{array}$ & $\begin{array}{c}-0.010 \\
{[0.000]}\end{array}$ & $\begin{array}{c}-0.068 \\
{[0.004]}\end{array}$ & $\begin{array}{c}-0.114 \\
{[0.000]}\end{array}$ \\
\hline Default Spread & $\begin{array}{c}0.590 \\
{[0.000]}\end{array}$ & $\begin{array}{c}0.415 \\
{[0.000]}\end{array}$ & $\begin{array}{c}0.501 \\
{[0.000]}\end{array}$ & $\begin{array}{c}0.327 \\
{[0.018]}\end{array}$ \\
\hline Intercept & $\begin{array}{c}-1.293 \\
{[0.018]}\end{array}$ & $\begin{array}{c}-0.552 \\
{[0.316]}\end{array}$ & $\begin{array}{c}-0.792 \\
{[0.144]}\end{array}$ & $\begin{array}{c}0.090 \\
{[0.869]}\end{array}$ \\
\hline Obs. & 564 & 564 & 564 & 564 \\
\hline Adjusted $R^{2}$ & 0.128 & 0.132 & 0.184 & 0.195 \\
\hline
\end{tabular}
Sentiment Levels

Table 2 reports the results of the following regressions,

$$
\begin{gathered}
\text { sent }_{t}=\beta_{0}+\beta_{1} \text { DemP }_{t}+\beta_{2-{ }_{6}} C V_{t}+\varepsilon_{t} \\
\text { sent }_{t}=\beta_{0}+\beta_{1} \text { DemP }_{t}+\beta_{2} \text { FirstYear }_{t}+\beta_{3} \text { ThirdYear }_{t} \\
+\beta_{4} \text { Change }_{\mathrm{t}}+\beta_{5-9} C V_{t}+\varepsilon_{t}
\end{gathered}
$$

where sent ${ }_{t}$ is the investor sentiment level index, $\operatorname{DemP}_{t}$ is the political variable, FirstYear ${ }_{t}$ is a dummy variable which is set to 1 if month $t$ is in the first year of president's tenure, and 0; otherwise, ThirdYear ${ }_{t}$ is a dummy variable which is set to 1 if month $t$ is the third year of president's tenure, and 0; otherwise, Change ${ }_{\mathrm{t}}$ is set to 1 at month $t$ if the president is of a different political party than his predecessor; and 0 ; otherwise, and $C V_{t}$ is the set of business cycle controls defined earlier. DemP $P_{t}$ is the political variable, and $C V_{t}$ is the set of business cycle controls defined earlier. $\varepsilon_{t}$ is the heteroskedastic error term in month $t$. For robustness, we use two indices of the sentiment level index. The first index (sent) is based on proxies of investor sentiment but not orthogonalized to macroeconomic trends. The second index (sent') is also based on proxies of investor sentiment and orthogonalized to macroeconomic trends. The term spread is the difference between the yield to maturity of a 10-year Treasury note and a three-month Treasury bill, the default spread is the difference between yields of BAA-rated bonds and AAA-rated bonds, the relative interest rate calculated as the deviation of the three-month Treasury bill rate from its one-year moving average, the inflation rate is obtained from FRED and the log dividendprice ratio is the log of the dividend-price ratio obtained from CRSP. p-values are in parentheses. 


\subsection{Political Cycles and Investor Sentiment Changes}

To better comprehend the relationship between political cycles and investor sentiment, we go beyond the sentiment levels and examine the sentiment changes during a president's tenure. To do so, we replace our dependent variable with the investor sentiment changes indexes and re-estimate our first two regressions.

$$
\text { sentc }_{t}=\beta_{0}+\beta_{1} \operatorname{DemP}_{t}+\beta_{2-6} C V_{t}+\varepsilon_{t}
$$

where sentc $c_{t}$ is the investor sentiment changes index in month $t$, DemP $P_{t}$ is set to 1 in month $t$ if the president is a Democrat; $\operatorname{DemP}_{t}$ is set to 0 otherwise, and $C V_{t}$ is the set of business cycle control variables defined earlier. $\varepsilon_{t}$ is the heteroskedastic error term in month $t$.

$$
\begin{aligned}
\text { sent }_{t}= & \beta_{0}+\beta_{1} \text { DemP }_{t}+\beta_{2} \text { FirstYear }_{t}+\beta_{3} \text { ThirdYear }_{t} \\
& +\beta_{4} \text { Change }_{t}+\beta_{5-9} C V_{t}+\varepsilon_{t}
\end{aligned}
$$

where sentc $c_{t}$ is the investor sentiment changes index in month $t, \operatorname{DemP}_{t}$ is set to 1 in month $t$ if the president is a Democrat; $\operatorname{DemP}_{t}$ is set to 0 otherwise, FirstYear ${ }_{t}$ is a dummy variable which is set to 1 if month $t$ is in the first year of the president's tenure, and 0; otherwise, ThirdYear ${ }_{t}$ is a dummy variable which is set to 1 if month $t$ is the third year of president's tenure, and 0 ; otherwise, Change $_{\mathrm{t}}$ is set to 1 in month $t$ if the president is of a different political party than his predecessor; and 0 ; otherwise, and $C V_{t}$ is the set of business cycle controls defined earlier. $\varepsilon_{t}$ is the heteroskedastic error term in month $t$.

The results, presented in Table 3, are generally consistent with our sentiment level results in Table 2. Column 1 of Table 3 shows a positive and statistically significant coefficient estimate of $\operatorname{Dem} P_{t}$, suggesting that investor sentiment improves during Democratic presidential terms. Combining with the results from Table 2, the result also suggests that investor sentiment levels although lower, tend to improve during Democratic presidential terms. This finding is consistent with studies that find that stock market returns are higher during Democratic presidential terms [see [9] and [10]]. Investors are generally more optimistic about the market during periods of high market returns.

The results of regression (4) are presented in column 2 of Table 3. Consistent with Table 2, the coefficient estimates for the first year dummy are not statistically different from zero, suggesting that investor sentiment does not change significantly in the first year of a president's tenure. This finding is consistent with the beginning of the investor learning process discussed earlier.

Additionally, the coefficient estimates for the third year dummy are statistically significant at the $1 \%$ level, however, they are positive. This finding suggests that investor sentiment significantly improves in the third year, a finding inconsistent with our earlier result that sentiment levels are lower in the third year.

To investigate the apparent inconsistency in the third year dummy results, we bifurcate the sample by presidential political party and compute the means, medians, and t-test the difference of means, for investor sentiment level indexes and investor sentiment change indexes. The results are presented in Table 4. Interestingly, the investor sentiment level indexes' means and medians are positive during Republican presidential terms and negative during Democratic presidential terms. However, the investor sentiment changes indexes' means and medians are negative during Republican presidential terms and positive during Democratic presidential terms. This finding explains the apparent inconsistency between the sentiment level and sentiment changes results. Clearly, investor sentiment is low at the beginning and builds up during Democratic presidential terms. By the end of a Democratic presidential term, investor sentiment is high and wanes during the subsequent Republican presidential term.

\begin{tabular}{|c|c|c|c|c|}
\hline & \multicolumn{2}{|c|}{ (3) } & \multicolumn{2}{|c|}{ (4) } \\
\hline & sent & sent' & sent & sent' \\
\hline $\operatorname{DemP}_{t}$ & $\begin{array}{c}0.225 \\
{[0.011]}\end{array}$ & $\begin{array}{c}0.303 \\
{[0.004]}\end{array}$ & $\begin{array}{c}0.258 \\
{[0.004]}\end{array}$ & $\begin{array}{c}0.342 \\
{[0.000]}\end{array}$ \\
\hline First Year & & & $\begin{array}{c}0.099 \\
{[0.241]}\end{array}$ & $\begin{array}{c}0.102 \\
{[0.412]}\end{array}$ \\
\hline Third Year & & & $\begin{array}{c}0.252 \\
{[0.002]}\end{array}$ & $\begin{array}{c}0.341 \\
{[0.000]}\end{array}$ \\
\hline Change & & & $\begin{array}{c}-0.239 \\
{[0.086]}\end{array}$ & $\begin{array}{c}-0.274 \\
{[0.088]}\end{array}$ \\
\hline Log div/price & $\begin{array}{c}0.191 \\
{[0.185]}\end{array}$ & $\begin{array}{c}0.167 \\
{[0.218]}\end{array}$ & $\begin{array}{c}0.137 \\
{[0.293]}\end{array}$ & $\begin{array}{c}0.099 \\
{[0.452]}\end{array}$ \\
\hline Term Spread & $\begin{array}{c}-0.025 \\
{[0.480]}\end{array}$ & $\begin{array}{c}-0.036 \\
{[0.435]}\end{array}$ & $\begin{array}{c}-0.016 \\
{[0.644]}\end{array}$ & $\begin{array}{c}-0.025 \\
{[0.592]}\end{array}$ \\
\hline Relative Rate & $\begin{array}{c}0.026 \\
{[0.630]}\end{array}$ & $\begin{array}{c}-0.100 \\
{[0.155]}\end{array}$ & $\begin{array}{c}0.031 \\
{[0.561]}\end{array}$ & $\begin{array}{c}-0.095 \\
{[0.176]}\end{array}$ \\
\hline Inflation Rate & $\begin{array}{c}-0.012 \\
{[0.378]}\end{array}$ & $\begin{array}{c}-0.012 \\
{[0.601]}\end{array}$ & $\begin{array}{c}-0.005 \\
{[0.683]}\end{array}$ & $\begin{array}{c}-0.004 \\
{[0.858]}\end{array}$ \\
\hline Default Spread & $\begin{array}{c}-0.056 \\
{[0.662]}\end{array}$ & $\begin{array}{c}0.122 \\
{[0.236]}\end{array}$ & $\begin{array}{c}-0.025 \\
{[0.854]}\end{array}$ & $\begin{array}{c}0.157 \\
{[0.138]}\end{array}$ \\
\hline Intercept & $\begin{array}{c}0.737 \\
{[0.245]}\end{array}$ & $\begin{array}{c}0.448 \\
{[0.469]}\end{array}$ & $\begin{array}{c}0.403 \\
{[0.492]}\end{array}$ & $\begin{array}{c}0.032 \\
{[0.960]}\end{array}$ \\
\hline Obs. & 564 & 564 & 564 & 564 \\
\hline Adjusted $R^{2}$ & 0.019 & 0.031 & 0.035 & 0.058 \\
\hline
\end{tabular}

Table 3. Relationship between Political Cycles and Investor Sentiment Changes

Table 3 reports the results of the following regressions,

$$
\begin{gathered}
\text { sentc }_{t}=\beta_{0}+\beta_{1} \text { DemP }_{t}+\beta_{2-6} C V_{t}+\varepsilon_{t} \\
\text { sentc }_{t}=\beta_{0}+\beta_{1} \text { DemP }_{t}+\beta_{2} \text { FirstYear }_{t}+\beta_{3} \text { ThirdYear }_{t} \\
+\beta_{4} \text { Change }_{\mathrm{t}}+\beta_{5-9} C V_{t}+\varepsilon_{t}
\end{gathered}
$$

where sent ${ }_{t}$ is the investor sentiment changes index, DemP $P_{t}$ is the political variable, FirstYear $r_{t}$ is a dummy variable which is set to 1 if month $t$ is in the first year of president's tenure, and 0 ; otherwise, ThirdYear $_{t}$ is a dummy variable which is set to 1 if month $t$ is the third year of president's tenure, and 0 ; otherwise, Change $e_{\mathrm{t}}$ is set to 1 at month $t$ if the president is of a different political party than his predecessor; and 0 ; otherwise, and $C V_{t}$ is the set of business cycle controls defined earlier. $\operatorname{DemP}_{t}$ is the political variable, and $C V_{t}$ is the set of business cycle controls defined earlier. $\varepsilon_{t}$ is the heteroskedastic error term in month $t$. For robustness, we use two indices of the sentiment changes index. For robustness, we use two indices of the sentiment level index. The first index (sent) is based on proxies of investor sentiment but not orthogonalized to macroeconomic trends. The second index (sent') is also based on proxies of investor sentiment and orthogonalized to macroeconomic trends. The term spread is the difference between the yield to maturity of a 10-year Treasury note and a three-month Treasury bill, the default spread is the difference between yields of BAA-rated bonds and AAA-rated bonds, the relative interest rate calculated as the deviation of the three-month Treasury bill rate from its one-year moving average, the inflation rate is obtained from FRED and the log dividendprice ratio is the log of the dividend-price ratio obtained from CRSP. p-values are in parentheses. 
Table 4. Political Cycles, Sentiment Levels Index, and Sentiment Changes Index

\begin{tabular}{|c|c|c|c|c|c|}
\hline \multicolumn{6}{|c|}{ Panel A: Sentiment Level Index } \\
\hline & \multicolumn{2}{|c|}{ Sent } & \multicolumn{2}{|c|}{ sent' } & \multirow[b]{2}{*}{$N$} \\
\hline Variable & Mean & Median & Mean & Median & \\
\hline Democrat $[D]$ & -0.236 & -0.081 & -0.214 & -0.007 & 228 \\
\hline Republican[R] & 0.152 & 0.025 & 0.138 & 0.056 & 336 \\
\hline Difference $[R-D]$ & 0.388 & & 0.352 & & \\
\hline$p$-value & 0.000 & & 0.000 & & \\
\hline \multicolumn{6}{|c|}{ Panel B: Sentiment Changes Index } \\
\hline Democrat $[D]$ & 0.150 & 0.101 & 0.169 & 0.172 & 228 \\
\hline Republican $[R]$ & -0.093 & -0.061 & -0.105 & -0.067 & 336 \\
\hline Difference $[R-D]$ & -0.243 & & -0.274 & & \\
\hline$p$-value & 0.008 & & 0.004 & & \\
\hline
\end{tabular}

Table 4 reports the means, medians, and t-test of the difference of means, for investor sentiment level indexes and investor sentiment change indexes by presidential political party subsample.

Next, we examine the trends in investor sentiment level and investor sentiment changes during Democratic and Republican presidential tenures. To do so, we find the means of the investor sentiment level index and investor sentiment changes index for each of the four years of each political party's presidents' tenure. Figure 1 presents a plot of the trends in investor sentiment during Democratic and Republican presidents' tenures and shows that investor sentiment level is low at the inception of a Democratic presidency, improves throughout the tenure, and declines during the subsequent Republican presidency. This finding is consistent with the positive investor sentiment changes during a Democratic presidency and negative investor sentiment changes during a Republican presidency.

\subsection{Political Cycles, Investor Sentiment Changes, and Stock Market Returns}

We have established that political cycles are correlated with investor sentiment. Next, following the [9] methods, we examine stock market returns and confirm the relationship between political cycles and stock market returns. To do so, we divide the sample by presidential political party and examine realized and excess market returns. We examine monthly as well as annualized market returns and find the difference of means between the two subsamples using a t-test. For robustness, we also divide the sample period into two equal subsample periods and repeat our tests. The results are presented in Table 5.

Consistent with [9] we find that realized as well as excess market returns are higher during Democratic presidencies, supporting our third hypothesis that the average stock market return during a Democratic presidency is higher than the average stock market return during a Republican presidency. For the full sample, the average monthly excess return is ten times higher in a Democratic presidency than in a Republican presidency, with the differences statistically significant at the 5\% level. These results are further confirmed in the subsamples, although, some of the difference of means tests lack statistical power due to the decreased sample size. A similar trend is observed in the annual data presented in panel B.

Table 5. Political Cycles and Market Returns in Percentage Points

\begin{tabular}{|c|c|c|c|c|c|c|c|c|c|}
\hline & \multicolumn{3}{|c|}{$1965-2011$} & \multicolumn{3}{|c|}{$\underline{1965-1988}$} & \multicolumn{3}{|c|}{$\underline{1989-2011}$} \\
\hline & $D$ & $R$ & Diff & $D$ & $R$ & Diff & $D$ & $R$ & Diff \\
\hline & \multicolumn{9}{|c|}{ Panel A: Monthly Data } \\
\hline$V W R-R F$ & 1.00 & 0.10 & $\begin{array}{c}0.90 \\
{[0.00]}\end{array}$ & 1.05 & -0.01 & $\begin{array}{c}1.06 \\
{[0.06]}\end{array}$ & 0.92 & 0.17 & $\begin{array}{c}0.75 \\
{[0.09]}\end{array}$ \\
\hline$V W R$ & 1.22 & 0.49 & $\begin{array}{c}0.71 \\
{[0.04]}\end{array}$ & 1.16 & 0.23 & $\begin{array}{c}0.93 \\
{[0.10]}\end{array}$ & 1.31 & 0.64 & $\begin{array}{c}0.67 \\
{[0.13]}\end{array}$ \\
\hline$R F$ & 0.21 & 0.38 & $\begin{array}{c}-0.17 \\
{[0.00]}\end{array}$ & 0.11 & 0.24 & $\begin{array}{c}-0.13 \\
{[0.00]}\end{array}$ & 0.39 & 0.47 & $\begin{array}{c}-0.08 \\
{[0.00]}\end{array}$ \\
\hline \multirow[t]{2}{*}{$N$} & 228 & 336 & & 96 & 192 & & 132 & 144 & \\
\hline & \multicolumn{9}{|c|}{$\underline{\text { Panel B: Annual Data }}$} \\
\hline$V W R-R F$ & 12.62 & 1.65 & $\begin{array}{c}10.97 \\
{[0.02]}\end{array}$ & 13.17 & -0.16 & $\begin{array}{c}13.33 \\
{[0.06]}\end{array}$ & 11.59 & 2.74 & $\begin{array}{c}8.85 \\
{[0.15]}\end{array}$ \\
\hline$V W R$ & 15.21 & 6.41 & $\begin{array}{c}8.80 \\
{[0.05]}\end{array}$ & 14.57 & 2.75 & $\begin{array}{c}11.82 \\
{[0.10]}\end{array}$ & 16.42 & 8.60 & $\begin{array}{c}7.82 \\
{[0.20]}\end{array}$ \\
\hline$R F$ & 2.60 & 4.75 & $\begin{array}{c}-2.15 \\
{[0.00]}\end{array}$ & 1.40 & 2.92 & $\begin{array}{c}-1.52 \\
{[0.01]}\end{array}$ & 4.83 & 5.86 & $\begin{array}{c}-1.03 \\
{[0.34]}\end{array}$ \\
\hline$N$ & 19 & 28 & & 8 & 16 & & 11 & 12 & \\
\hline
\end{tabular}

Table 5 reports the realized and excess market returns by presidential political party subsample; Democratic presidential terms (D) and Republican presidential terms $(R)$. For stock market returns, we use the monthly returns of value-weighted (VWR) portfolios from CRSP. For the risk-free rate $(R F)$, we use the three-month Treasury bill rate. We examine monthly as well as annualized returns and find the difference of means (Diff) between the two subsamples using a t-test. For robustness, we also divide the sample period into two subsample periods and repeat our tests. 


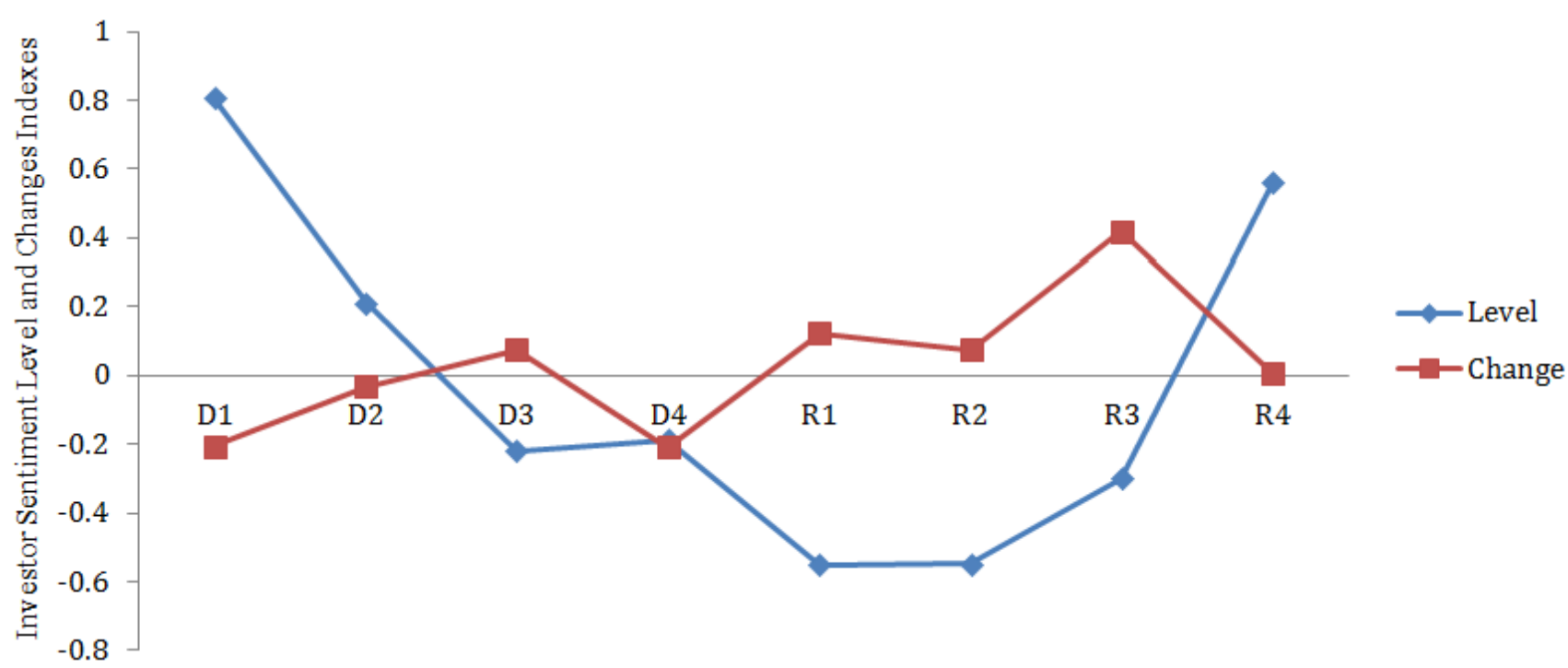

Figure 1 shows the average investor sentiment level and average investor sentiment changes index for Democratic [D] presidential tenure and Republican[R] presidential tenure from year 1 to year 4 .

Figure 1. Investor Sentiment Level and Changes Indexes during a Presidential Tenure

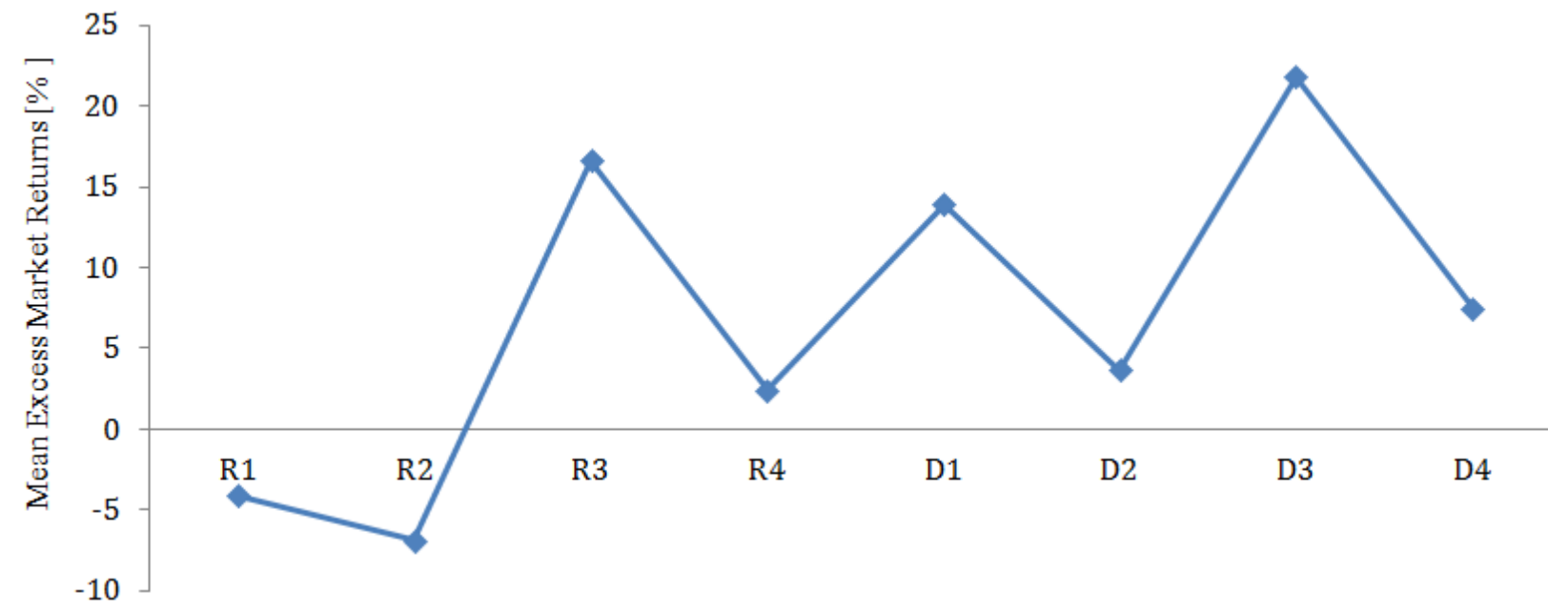

Figure 2 shows the average excess market returns for Republican[R] presidential tenure and Democratic [D] presidential tenure from year 1 to year 4.

Figure 2. Mean Excess Market Returns during a Presidential Tenure

Next, we track trends in stock market returns during Democratic and Republican presidential tenures. Figure 2 presents a plot of mean annual stock market returns against presidential tenure in years. Consistent with our earlier results, returns are higher during Democratic presidencies than Republican presidencies.

Combining Figure 1 and Figure 2, we observe that investor sentiment level seems to be positively (negatively) correlated with stock returns during a Democratic (Republican) presidency. To confirm our conjecture, we run the correlation between investor sentiment levels and stock returns, and present the results in Table 6 panel A. The negative correlation coefficient for the full sample is consistent with the findings of [6]. However, the finding is counterintuitive and so we investigate further. To do so, we bifurcate the sample by presidential political party and run the correlation between investor sentiment levels and stock returns, and present the results in Table 6 panel B. The statistically significant correlation coefficients confirm our conjecture that beginning of period investor sentiment level is positively (negatively) correlated with stock returns during a Democratic (Republican) presidency.
Table 6. Investor Sentiment Level Index and Stock Market Return Correlations

\begin{tabular}{|c|c|c|c|c|}
\hline \multicolumn{5}{|c|}{ Panel A: Full Sample } \\
\hline Variable & VWR & Sent & & \\
\hline VWR & 1.000 & $\begin{array}{c}-0.149 \\
{[0.000]}\end{array}$ & & \\
\hline $\mathrm{N}$ & \multicolumn{2}{|c|}{545} & & \\
\hline \multicolumn{5}{|c|}{ Panel B: Partition by Presidential Political Party } \\
\hline & \multicolumn{2}{|c|}{ Democrats } & \multicolumn{2}{|c|}{ Republicans } \\
\hline Variable & VWR & Sent & VWR & Sent \\
\hline VWR & 1.000 & $\begin{array}{c}0.243 \\
{[0.000]}\end{array}$ & 1.000 & $\begin{array}{c}-0.223 \\
{[0.000]}\end{array}$ \\
\hline $\mathrm{N}$ & \multicolumn{2}{|c|}{209} & \multicolumn{2}{|c|}{336} \\
\hline
\end{tabular}

Table 6 reports the correlation coefficients between the beginning of period monthly orthogonalized investor sentiment level index (sent) and monthly value-weighted stock market returns. p-values are in parentheses. 
We infer that a Democratic president instills more optimism in the stock market which contributes to the higher returns (see [6] during the term. On the other hand, during a Republican presidency, investor sentiment level sequentially declines, but stock returns albeit lower, still hovers above the zero mark, leading to the negative correlation coefficient. Hence, by bifurcating the sample by presidential political party, we present more insight into the investor sentiment and stock market return relationship.

\subsection{Changes in Investor Sentiment mediates Political Cycles and Stock Market Returns}

In this section, we examine the behavioral finance link between political cycles and stock market returns. The indirect-link hypothesis indicates that the investor sentiment changes variable might be a mediator or a partial mediator between political cycles and stock market returns. To investigate these links, naturally, we visit the behavioral science literature and employ the mediation models of [15] and [16].

Following [16], we identify the simple relationship between political cycles and stock market returns as the total effect of political cycles on stock market returns. Additionally, we identify the direct effect of political cycles on stock market returns as the effect after controlling for changes in investor sentiment changes. Specifically, according to [15], changes in investor sentiment is considered at least a partial mediator between political cycles and stock market returns, if the following conditions are met. The conditions are that political cycles significantly predict stock market returns, political cycles significantly predict investor sentiment, and investor sentiment significantly predicts stock market returns after controlling for political cycles.

Using the monthly data, we examine the links among political cycles, investor sentiment, and stock returns. Following Baron and Kenny, we employ the following set of OLS regression models;

$$
\begin{gathered}
R_{t}=\beta_{0}+\beta_{1} \operatorname{DemP}_{t-1}+\beta_{2-6} C V_{t}+\varepsilon_{t} \\
\text { sentc }_{t}=\beta_{0}+\beta_{1} \operatorname{DemP}_{t-1}+\beta_{2-6} C V_{t}+\varepsilon_{t} \\
R_{t}=\beta_{0}+\beta_{1} \operatorname{DemP}_{t-1}+\beta_{2} \text { sentc }_{t-1}+\beta_{2-6} C V_{t}+\varepsilon_{t}
\end{gathered}
$$

where $R_{t}$ is the monthly value-weighted (VWR) portfolio return in month $t$, sent $c_{t}$ is the investor sentiment changes index in month $t$, sentc $c_{t-1}$ is the investor sentiment changes index in month $t-1$. DemP $P_{t-1}$ is set to 1 in month $t-1$ if the president is a Democrat; $\operatorname{Dem} P_{t-1}$ is set to 0 otherwise, $C V_{t}$ is the set of business cycle controls defined earlier, and $\varepsilon_{t}$ is the heteroskedastic error term in month $t$. We replace sentc with sentc' and re-estimate the set of OLS regressions.

The results of the set of OLS regressions are presented in Table 7 panel A. The political cycles coefficient is statistically significant at the $5 \%$ level and indicates that political cycles predict stock market returns. Political cycles predict changes in investor sentiment, sentc (sentc'); with the political cycles coefficient statistically significant at the $5 \%(1 \%)$ level. Additionally, changes in investor sentiment predict stock market returns after controlling for political cycles; with the sentc (sentc') coefficient statistically significant at the $1 \%(1 \%)$ level. These findings collectively support our hypothesis that changes in investor sentiment is a mediator between political cycles and stock market returns, and support our conjecture that the effect of political cycles on stock market returns is twofold; the direct effect of fiscal policies on corporate fundamentals and the indirect effect through changes in investor sentiment.

For robustness, we further assess the mediation hypothesis using the Sobel test, developed by [17] and described in [15]. For simple mediation, the Sobel test is conducted by testing whether the power of the indirect effect of political cycles on stock market returns is significantly different from zero. The indirect effect of political cycles on stock market returns, in this particular case, is defined as the product of the political cycles to changes in investor sentiment path $(a)$ and the changes in investor sentiment to stock market returns path $(b)$, or $a b$. Standard errors of $a$ and $b$ are, respectively, $s_{a}$ and $s_{b}$, and, according to [17], the standard error of the indirect effect $\left(s_{a b}\right)$ is computed as $s_{a b}=\sqrt{b^{2} s_{a}^{2}+a^{2} s_{b}^{2}+s_{a}^{2} s_{b}^{2}}$. With the product of the coefficients $(a b)$ and the standard error $\left(s_{a b}\right)$, a critical ratio is computed; $a b$ divided by $s_{a b}$, and compared with the $\mathrm{z}$ value (critical value from the standard normal distribution table) for a given $\alpha$ level.

The results of the Sobel test are presented in Table 7 panel $\mathrm{B}$. We find that the Sobel critical ratio using sentc is 2.18 which is statistically significant at the $5 \%$ level, and the Sobel critical ratio using sentc' is 2.97 which is statistically significant at the $1 \%$ level. The Sobel test results present further evidence that changes in investor sentiment is a mediator between political cycles and stock market returns.

\section{Conclusion}

In this study, we present links among political cycles, investor sentiment, and stock market returns. First, we empirically examine the relationship between presidential elections cycles and investor sentiment, and find that investor sentiment levels are lower during Democratic presidential terms than Republican presidential terms. Next, we find that investor sentiment changes are generally positive during Democratic presidential terms and negative during Republican presidential terms. Our second finding seems inconsistent with our first finding. However, further analysis reveals that investor sentiment is low at the commencement of a Democratic presidential term and improves during the term. By the end of a Democratic presidential term, investor sentiment is high and wanes during the subsequent Republican presidential term. Additionally, investor sentiment is generally higher following a change in the political party in the White House.

Additionally, we find that realized as well as excess returns are higher during Democratic presidencies than Republican presidencies and our finding is consistent with that of [9]. These findings suggest that Democratic fiscal and regulatory policies are still more expansionary than Republican policies. 
Table 7. Political Cycles, Changes in Investor Sentiment, and Stock Market Returns

\begin{tabular}{|c|c|c|c|c|c|}
\hline \multirow[t]{2}{*}{ Panel A } & \multicolumn{3}{|c|}{ Sentc } & \multicolumn{2}{|c|}{ sentc' } \\
\hline & (5) & (6) & (7) & (6) & (7) \\
\hline \multirow{2}{*}{$\operatorname{Dem} P_{t-1}$} & 0.900 & 0.223 [a] & 0.675 & $0.300[\mathrm{a}]$ & 0.440 \\
\hline & [0.037] & [0.019] & {$[0.107]$} & {$[0.002]$} & {$[0.282]$} \\
\hline \multirow{2}{*}{$S C I_{t-1}$} & & & $1.163[\mathrm{~b}]$ & & $1.580[\mathrm{~b}]$ \\
\hline & & & {$[0.000]$} & & {$[0.000]$} \\
\hline \multirow{2}{*}{ Log div/price } & 1.444 & 0.198 & 1.290 & 0.170 & 1.184 \\
\hline & [0.019] & [0.141] & {$[0.030]$} & [0.205] & {$[0.040]$} \\
\hline \multirow{2}{*}{ Term Spread } & 0.041 & -0.028 & 0.061 & -0.038 & 0.124 \\
\hline & 0.041 & {$[0.510]$} & [0.749] & [0.372] & {$[0.502]$} \\
\hline \multirow{2}{*}{ Relative Rate } & -0.646 & 0.023 & -0.679 & -0.102 & -0.539 \\
\hline & [0.017] & [0.693] & [0.010] & {$[0.084]$} & {$[0.035]$} \\
\hline \multirow{2}{*}{ Inflation Rate } & -0.204 & -0.014 & -0.207 & -0.012 & -0.175 \\
\hline & {$[0.044]$} & [0.542] & {$[0.034]$} & {$[0.574]$} & [0.065] \\
\hline \multirow{2}{*}{ Default Spread } & -0.129 & -0.060 & 0.059 & 0.120 & -0.296 \\
\hline & [0.794] & [0.582] & [0.902] & [0.267] & {$[0.526]$} \\
\hline \multirow{2}{*}{ Intercept } & 6.132 & 0.780 & 5.460 & 0.466 & 5.317 \\
\hline & [0.023] & [0.187] & {$[0.037]$} & {$[0.427]$} & {$[0.036]$} \\
\hline Obs. & 543 & 543 & 543 & 543 & 543 \\
\hline Adjusted $R^{2}$ & 0.027 & 0.089 & 0.020 & 0.027 & 0.142 \\
\hline \multicolumn{2}{|l|}{ Panel B } & \multicolumn{2}{|c|}{ sentc } & \multicolumn{2}{|c|}{ sentc' } \\
\hline \multicolumn{2}{|l|}{$A$} & \multicolumn{2}{|c|}{0.223} & \multicolumn{2}{|c|}{0.300} \\
\hline \multicolumn{2}{|l|}{$B$} & \multicolumn{2}{|c|}{1.163} & \multicolumn{2}{|c|}{1.580} \\
\hline \multicolumn{2}{|l|}{$s_{a}$} & \multicolumn{2}{|c|}{0.094} & \multicolumn{2}{|c|}{0.094} \\
\hline \multicolumn{2}{|l|}{$s_{b}$} & \multicolumn{2}{|c|}{0.191} & \multicolumn{2}{|c|}{0.186} \\
\hline \multicolumn{2}{|l|}{$A b$} & \multicolumn{2}{|c|}{0.259} & \multicolumn{2}{|c|}{0.474} \\
\hline \multicolumn{2}{|l|}{$s_{a b}$} & \multicolumn{2}{|c|}{0.119} & \multicolumn{2}{|c|}{0.159} \\
\hline Critical ratio $=a b / s_{a b}$ & & & & & \\
\hline [p-value] & & & & & \\
\hline
\end{tabular}

Panel A presents the results of the assessment of the interactions among political cycles, investor sentiment changes, and stock market returns by employing the following set of OLS regression models;

$$
\begin{gathered}
R_{t}=\beta_{0}+\beta_{1} \operatorname{DemP}_{t-1}+\beta_{2-6} C V_{t}+\varepsilon_{t} \\
\text { sentc }_{t}=\beta_{0}+\beta_{1} \operatorname{DemP}_{t-1}+\beta_{2-6} C V_{t}+\varepsilon_{t} \\
R_{t}=\beta_{0}+\beta_{1} \operatorname{DemP}_{t-1}+\beta_{2} \text { sentc }_{t-1}+\beta_{2-6} C V_{t}+\varepsilon_{t}
\end{gathered}
$$

where $R_{t}$ is the monthly value-weighted $(V W R)$ portfolio return in month $t$, sent $c_{t}$ is the investor sentiment changes index in month $t$, sent $c_{t-1}$ is the investor sentiment changes index in month $t-1$; we use two versions of the investor sentiment changes index. DemP $P_{t-1}$ is set to 1 in month $t-1$ if the president is a Democrat; $\operatorname{Dem} P_{t-1}$ is set to 0 otherwise, $C V_{t}$ is the set of business cycle controls defined earlier, and $\varepsilon_{t}$ is the heteroskedastic error term in month $t$. We replace sentc with sentc' and re-estimate the set of OLS regressions. The first sentiment changes index (sentc) is based on changes in nonorthogonalized investor sentiment level index. The second sentiment changes index (sentc') is based on based on changes in orthogonalized investor sentiment level index. p-values are in parentheses. Panel B presents the results of the Sobel test conducted by testing whether the power of the indirect effect of political cycles on stock market returns is significantly different from zero. The indirect effect of political cycles on stock market returns is defined as the product of the political cycles to investor sentiment changes path $(a)$ and the investor sentiment changes to stock market returns path $(b)$, or $a b$. Standard errors of $a$ and $b$ are, respectively, $s_{a}$ and $s_{b}$, and, according to Sobel (1982), the standard error of the indirect effect ( $s_{a b}$ ) is computed as $s_{a b}=\sqrt{b^{2} s_{a}^{2}+a^{2} s_{b}^{2}+s_{a}^{2} s_{b}^{2}}$. With the product of the coefficients $(a b)$ and the standard error $\left(s_{a b}\right)$, a critical ratio is computed; $a b$ divided by $s_{a b}$, and compared with the $\mathrm{z}$ value (critical value from the standard normal distribution table) for a given $\alpha$ level.

Previous studies have established a link between political cycles and stock market returns (see [9] and a link between investor sentiment and stock returns (see [6]). In this study, we extend the extant research on investor sentiment, by presenting a link among political cycles, changes in investor sentiment, and stock market returns. We find that variable: change in investor sentiment levels, is a mediator in the relationship between political cycles and stock market returns. We conclude that the effect of political cycles on stock market returns occurs through two channels. First, there is a direct impact of fiscal and regulatory policies on corporate fundamentals which is reflected in stock prices, and second, there is an indirect impact through the change in investor sentiment levels which in turn impacts stock prices.

\section{References}

[1] Herbst, Anthony, and Craig. W. Slinkman. "Political economic cycles in the U.S. stock market.” Financial Analysts Journal 4.2 (1984): 35-39. 
[2] Huang, Roger. "Common stock returns and presidential elections” Financial Analysts Journal 41.2 (1985), 58-61.

[3] Alesina, Alberto. "Macroeconomic policy in a two-party system as a repeated game.” Quarterly Journal of Economics 102 (1987): 651-678.

[4] Alesina, Alberto, Nouriel Roubini, and Gerald D. Cohen. "Political Cycles and the Macroeconomy.” MIT Press, Cambridge, MA(1997).

[5] Drazen, Allan. "Political Economy in Macroeconomics." Princeton University Press, Princeton, NJ (2000).

[6] Baker, Malcolm, and Jeffrey Wurgler. "Investor Sentiment and the Cross-Section of Stock Returns.” Journal of Finance 61 (2006): 1645-1680.

[7] Hensel, Chris R., and William T. Ziemba. "United States investment returns during Democratic and Republican administrations, 1928-1993.” Financial Analysts Journal 4.2 (1995), 61-69.

[8] Chittenden,William, Gerald R. Jensen, and Robert R. Johnson. "Presidential politics, stocks, bonds, bills, and inflation.” Journal of Portfolio Management 26 (1999): 63- 79.

[9] Santa-Clara, Pedro, and Rossen Valkanov. "The presidential puzzle: Political cycles and the stock market.” Journal of Finance 58 (2003): 1841-1872.
[10] Belo, Frederico, Vito D. Gala, and Jun Li. "Government spending, political cycles, and the cross section of stock returns.” Journal of Financial Economics 107.2 (2013): 305-324.

[11] DeLong, J.B., Andrei Shleifer, Lawrence H. Summers, and Robert J. Waldmann. "Noise Trader Risk in Financial Markets.” Journal of Political Economy 98.4 (1993): 703-738.

[12] Lee, Charles M.C., Andrei Shleifer, and Richard H. Thaler. "Investor Sentiment and the Closed-End Fund Puzzle." Journal of Finance 46 (1991): 75-109.

[13] Baker, Malcolm, and Jeremy Stein. "Market Liquidity as a Sentiment Indicator.” Journal of Financial Markets 7.3 (2004): 271-99.

[14] Stigler, George J. "Public regulation of the securities markets." Journal of Business 37 (1964): 117-142.

[15] Baron, Reuben, and David Kenny. "The Moderator-Mediator Variable Distinction in Social Psychological Research: Conceptual, Strategic, and Statistical Considerations.” Journal of Personality and Social Psychology 51.6 (1986): 1173- 1182.

[16] Preacher, Kristopher, and Andrew Hayes. "SPSS and SAS Procedures for Estimating Indirect Effects in Simple Mediation Models.” Behavior Research Methods, Instruments, and Computers 36.4 (2004): 717-731.

[17] Sobel, Michael. "Asymptotic Confidence Intervals for Indirect Effects in Structural Equation Models.” Sociological Methodology 13 (1982): 290-312. 